\title{
Dental Development and the Evolution of Life History in Hominidae
}

\author{
B. HOLLY SMITH \\ Museum of Anthropology, The University of Michigan, Ann Arbor, \\ Michigan 48109
}

\author{
KEY WORDS Primates, Ontogeny, Australopithecus
}

\begin{abstract}
Development of the dentition is critically integrated into the life cycle in living mammals. Recent work on dental development has given rise to three separate lines of evidence on the evolution of human growth and aging; these three, based on several independent studies, are reviewed and integrated here. First, comparative study of living primate species demonstrates that measures of development (e.g., age of emergence of the first permanent molar) are highly correlated with the morphological attributes brain and body weight (as highly as $r=0.98, \mathrm{~N}=21$ species). These data predict that small-bodied, small-brained Australopithecus erupted $\mathrm{M}_{1}$ at 3-3.5 years and possessed a life span comparable to that of a chimpanzee. Second, chronological age at death for three australopithecines who died at or near emergence of $\mathrm{M}_{1}$ is now estimated as $\sim 3.25$ years based on incremental lines in teeth; this differs substantially from expectations based on human growth schedules (5.5-6 years). Third, developmental sequences (assessed by the coefficient of variation of human dental age) observed in gracile Australopithecus and great apes diverge from those of humans to a comparable degree; sequences become more like modern humans after the appearance of the genus Homo. These three lines of evidence agree that the unique rate and pattern of human life history did not exist at the australopithecine stage of human evolution. It is proposed that the life history of early Homo matched no living model precisely and that growth and aging evolved substantially in the Hominidae during the last 2 million years.
\end{abstract}

The "life history" of early human ancestors is of interest for three reasons. First, reconstructions of the timing of somatic maturity, sexual maturity, and life span of extinct species serve to bring the past to life. Second, life history has an important place in theories of the evolution of human biology, behavior, and culture. Third, human evolution is an important test case for general theories about the evolution of growth and aging because humans are at extremes for developmental parameters in mammals. Despite a modest body size, humans have long gestation, prolonged infant and juvenile dependency, delayed reproduction, and the longest life span of any living mammal (see Sacher, 1975). It is thus of special interest to know how and when humans evolved this extreme life history.

Substantial new information on the evolu- tion of human growth has appeared in recent years, much of it concerning development of the dentition. The dentition provides an important link between the growth of living and extinct species because it is a complex developmental system that is critically integrated into the life cycle in mammals and because it can be studied readily in the living or the dead. Here I review three separate lines of evidence on the evolution of human growth and aging derived from living primates and from the fossil record: first, the correlates of dental development and life history in living primate species; second, estimates of chronological age at death from counts of incremental lines in teeth of fossil hominids; and third, developmental se-

Received March 5, 1990; accepted February 27, 1991. 
quences observable in fossil hominids. The basic data underlying these lines of evidence are published in detail elsewhere (principally in Smith, 1989a; Bromage and Dean, 1985; Smith, 1986, 1989b, respectively). My purpose here is to integrate the three and to discuss their bearing on the question of the evolution of human life history.

\section{HISTORICAL PERSPECTIVE}

The special significance of human growth rate and life span has been a persistent theme in evolutionary theory and developmental anatomy for over 100 years (Huxley, 1863; Darwin, 1871; Bolk, 1926; Clark, 1947; Dart, 1948b; Keith, 1949; Schultz, 1960; Washburn, 1960; Dobzhansky, 1962; Montagu, 1962; Mann, 1972; Sacher, 1975; Gould, 1977). If literary and philosophical interpretations are added, the topic spans centuries (see Lovejoy, 1922). For living mammals, comparative studies link prolonged juvenile dependency and long life with enlarged brains, enhanced learning and sociality, increased parental investment, and increasingly complex behavior (e.g., Pianka, 1970; Martin, 1983; Lillegraven et al., 1987). In discussions of early human evolution, prolonged infant and juvenile dependency appears consistently as a primary factor in the evolution of a home base, food sharing, male hunting, and evolution of mating patterns and family structure (Bartholomew and Birdsell, 1953; Etkin, 1954; Washburn, 1960; Isaac, 1978; Lancaster, 1978; Lovejoy, 1981).

The full range of opinion on the fossil record of human growth was in place at an early date. Dart's 1925 announcement of Australopithecus suggested that humanlike maturation existed in earliest Hominidae by comparing the Taung child to a 6-year-old human child, an idea Dart (1948a,b) developed in later work. At the opposite extreme, Bolk (1926) claimed to have demonstrated that even the relatively recent Neanderthals developed more rapidly than modern humans.

The principal clues to growth and development of extinct hominids came from the dentition, but no consensus appeared in early work as to nature of this evidence. Drennan (1932), Weidenreich (1937), Dart (1948a), and Senyurek (1955) noted what they considered to be primitive developmental sequences in teeth of fossil hominids; Clark (1947) and Broom and Robinson (1951) emphasized developmental similari- ties in australopithecine and modern human dentitions; Legoux (1966) thought he could identify different races of Neanderthals by dental development. Whatever their reservations (e.g., Vallois, 1937; McCown and Keith, 1939; Weidenreich, 1939), paleoanthropologists commonly assessed dental age in fossil hominids according to human standards.

Subsequently, Garn and associates (Garn et al., 1957; Koski and Garn, 1957) noted technical and methodological flaws in early studies, cautioning that many comparisons were poorly grounded. Tobias (1968) limited his discussion of age of death in Australopithecus to relative categories only.

In his thesis and later monograph, Mann $(1968,1975)$ made a direct approach to the question: When did human ancestors achieve a human level of growth and development? Mann (1975:77-78) took the position that events in crown formation, root formation, eruption, and occlusal wear, taken together, form a sequence of events interrelated with sufficient complexity that they have an ordered and meaningful relationship to rates of development. This was the underlying justification for Mann's comparison of developmental sequences in the dentition of australopithecines with that of extant humans and chimpanzees. His observations on four specimens of Australopithecus robustus from Swartkrans led him to propose that the prolonged juvenile growth and development characteristic of modern humans was ancient, its appearance perhaps associated with the origin of the Hominidae. Mann (1975:77) noted Biggerstaff's suggestion (1967) that the small body size of Australopithecus made likely a rapid maturation and short generation time, but dismissed this argument as being without supporting evidence. One important outcome of Mann's study was the argument that a human level of maturation indicated an advanced grade of evolution for Australopithecus, an advance that made them seem more "humanlike" and that suggested a dependence on culture for survival (see Mann, 1972, 1975; Pilbeam, 1972; Wolpoff, 1973).

Subsequent discovery of Australopithecus afarensis (Johanson et al., 1978) pushed back the date of appearance of the genus to more than 1 million years before the appearance of stone tools. This, and the morphological primitiveness of the new species, seemed in conflict with the view that Australopithecus was significantly advanced in grade of 
evolution (Johanson and White, 1979; Stern and Susman, 1983; Falk, 1985; Simons, 1989). Furthermore, results of new comparative studies of size and life history in mammals could not be reconciled with humanlike maturation in Australopithecus (see Sacher, 1975; Pilbeam, 1980; Martin, 1983).

By the mid-1980s, a good deal of relevant information had accumulated since Mann's original (1968) study: new juvenile fossils (White, 1977; Leakey and Leakey, 1978), a greater knowledge of dental development in humans and great apes (Moorrees et al., 1963; Tarrant and Swindler, 1972; Dean and Wood, 1981), comparative data on mammalian life history (Sacher and Staffeldt, 1974; Harvey and Clutton-Brock, 1985), and an increasing knowledge of incremental growth in hard tissues (see Bromage and Dean, 1985). Trinkaus (1984) revived the question of whether Neanderthals were perfectly modern in all aspects of growth and development; it was inevitable that Australopithecus would be reexamined also. Bromage (1985, 1987), Bromage and Dean (1985), Dean (1987a,b, 1989), Smith (1986, 1989a,b), Beynon and Wood (1987), Conroy and Vannier (1987), and Beynon and Dean (1987, 1988) have since concluded that the data do not support a human growth rate for Australopithecus. Bromage (1987) reinterprets Mann's original observations (see also Smith, 1987). Mann, in turn, apparently regards all these studies as incorrect (Lewin, 1987; Mann et al., 1987, 1990; Mann, 1988). This disagreement leaves the field with the full range of opinion, from that of Dart to Bolk, represented once again 60 years later in the contrast between Mann et al. (1987) and Dean et al. (1986).

\section{GROWTH AND DEVELOPMENT OF LIVING PRIMATES \\ Why study teeth?}

The dentition provides an important marker of life history in mammalian growth and development. Certainly Adolph Schultz recognized this; in his well-known illustration of the proportional increase in life periods in primates (redrawn in Fig. 1) he defined infantile, juvenile, and adult stages, respectively, as the periods before, during, and after eruption of the permanent teeth. It is quite reasonable that the dentition must be closely integrated into the overall plan of somatic growth and development; after all, it processes the food that fuels all growth. Teeth must emerge so that babies can be

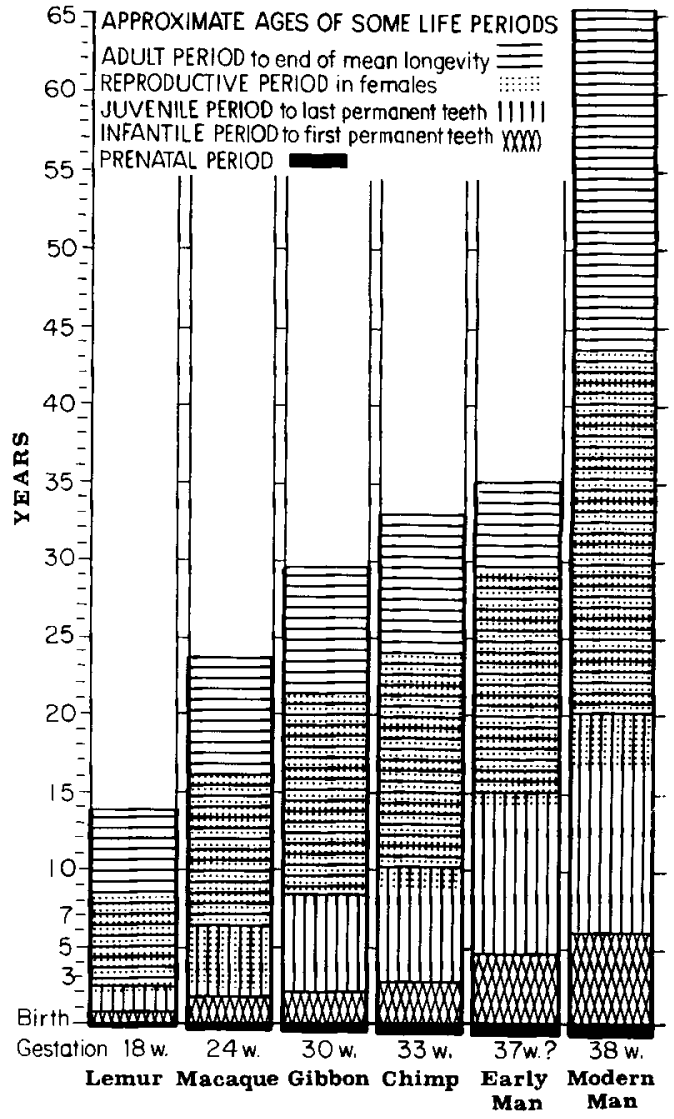

Fig. 1. Classic illustration of proportional increases in length of periods of the life cycle across the primate scala naturae; redrawn from Schultz (1960). Note that "infantile, juvenile, and adult" periods are defined in relation to eruption of permanent teeth, the standard anatomical definition of these periods (Schultz, 1969: 147). Schultz included his conjecture of life history in human ancestors as the column "early man"-the subject of the present inquiry.

weaned, permanent ones must replace deciduous precursors before they wear out, and molars cannot emerge before there is sufficient growth in length of the face. Teeth must erupt serially in a manner that establishes a functional occlusion. For most mammals, complete wear and loss of teeth means the end of adequate food processing and nutrition and presumably death. Thus, for survival of an individual, timing of dental development is critical.

It is possible to do more than assert that dental development is well integrated into somatic growth and life cycle-recent compi- 
$T A B L E$ 1. Intercorrelation ( $r$ ) of a series of markers of life history across primate species ${ }^{1}$

\begin{tabular}{|c|c|c|c|c|}
\hline Life history variable & $\begin{array}{c}\text { Gestation } \\
\text { length }\end{array}$ & $\begin{array}{c}\text { Age of } \\
\text { weaning }\end{array}$ & $\begin{array}{c}\text { Age of female } \\
\text { sexual maturity }\end{array}$ & Life span \\
\hline Gestation length (days) & - & & & \\
\hline Age of weaning (days) & $\begin{array}{l}0.80 \\
(37)\end{array}$ & - & & \\
\hline Age of female sexual maturity (mos) & $\begin{array}{l}0.79 \\
(43)\end{array}$ & $\begin{array}{l}0.87 \\
(30)\end{array}$ & - & \\
\hline Life span (yr) & $\begin{array}{l}0.49 \\
(50)\end{array}$ & $\begin{array}{l}0.73 \\
(27)\end{array}$ & $\begin{array}{l}0.68 \\
(36)\end{array}$ & - \\
\hline Age of $M_{1}$ eruption ( $\left.y r\right)$ & $\begin{array}{l}0.85 \\
(18)\end{array}$ & $\begin{array}{l}0.93 \\
(14)\end{array}$ & $\begin{array}{l}0.86 \\
(13)\end{array}$ & $\begin{array}{l}0.85 \\
(14)\end{array}$ \\
\hline
\end{tabular}

${ }^{1}$ All variables transformed to logarithms (base 10). Data sources: Harvey and Clutton-Brock (1985) and Smith (1989a); number of species in correlations in parentheses.

lations of extensive data on primate life history support this claim explicitly. In Table 1, ages of appearance of a series of markers of maturation are correlated across primate species. Markers of prenatal, infantile, juvenile, and adult periods are taken from the compendium of Harvey and Clutton-Brock (1985) on 135 primate species. These data are correlated with age of emergence of the permanent mandibular first molar, at present known for 21 primate species (Smith, 1989a). In correlations, each primate species is represented by a single mean value for each variable; as is standard practice for such correlations made "across" an order of mammals, all variables are first transformed to logarithms.

First, Table 1 shows that measures of life history in a species are positively correlated in general. Species with long gestations wean later, reach sexual maturity later, and live longer than other species (see Harvey and Clutton-Brock, 1985:561). As shown in Table 1, they also erupt their teeth later. Age of emergence of the mandibular first molar is highly correlated with measures of life history based on reproduction or longevity, ranging from $r=0.85$ to $r=0.93$. Thus a growth marker based on hard tissues is strongly related to "soft tissue" measures of life history commonly discussed in studies of living mammals. The high intercorrelation of various markers of growth and aging emphasizes the interdependence and integration of the stages of life history in living primates.

Table 1 also shows one seeming peculiarity: Each variable is more highly correlated with age of tooth emergence than it is with other variables. This effect appears when all species are included, as in Table 1 , or when comparisons are limited to the 21 species with data for age of $M_{1}$ emergence, as in Smith (1989a). This may be due to a relatively low error inherent in dental development, especially when compared with the more plastic measures of life history commonly described for living mammals. Tooth development is well known to be relatively resistant to environmental effects (Lewis and Garn, 1960; Widdowson and McCance, 1960; Garn et al., 1965a,b; Niswander and Sujaku, 1965; Murchison et al., 1988), whereas growth parameters such as age of female sexual maturity are well known to be sensitive to nutrition and other secular factors (see Eveleth and Tanner, 1976). In addition, aspects of dental development are measurable with some precision. Low sensitivity to the environment and low measurement error may combine to make tooth development a good proxy for an overall rate of maturation in a species (Smith, 1989a).

\section{Brain size and life history}

As might be expected from the results in Table 1, there is evidence for an underlying size component in positive correlations among life history variables. The work of George Sacher and others (Sacher, 1959, 1975, 1978; Sacher and Staffeldt, 1974; Hofman, 1983; Martin, 1983; Harvey and Clutton-Brock, 1985) demonstrates that attributes of development are positively associated with the morphological attributes brain weight and body weight as studied across species in primates and other mammals. Table 2 presents the correlations of life history measures with body and brain weight in primates. Each variable is positively associated with body weight $(r=$ 
TABLE 2. Correlation of life history variables with body weight and brain weight across primate species

\begin{tabular}{|c|c|c|c|c|}
\hline \multirow[b]{2}{*}{ Life history variable } & \multirow[b]{2}{*}{$\begin{array}{l}\text { No. of } \\
\text { species }\end{array}$} & \multicolumn{2}{|c|}{ Simple correlation } & \multirow{2}{*}{$\begin{array}{c}\begin{array}{c}\text { Multiple } \\
\text { correlation }\end{array} \\
\begin{array}{c}\text { Brain and } \\
\text { body weight }\end{array}\end{array}$} \\
\hline & & $\begin{array}{c}\text { Body } \\
\text { weight }^{2}(\mathrm{~kg})\end{array}$ & $\begin{array}{c}\text { Brain } \\
\text { weight }^{3}(\mathrm{gm})\end{array}$ & \\
\hline Gestation length (days) & 71 & 0.66 & 0.71 & 0.72 \\
\hline Age of weaning (days) & 46 & 0.91 & 0.91 & 0.92 \\
\hline Age of female sexual maturity (mos) & 49 & 0.79 & 0.85 & 0.86 \\
\hline Life span (yr) & 51 & 0.76 & 0.79 & 0.79 \\
\hline Age of $\mathrm{M}_{1}$ eruption ( $\mathrm{yr}$ ) & 21 & 0.89 & 0.98 & 0.98 \\
\hline
\end{tabular}

${ }^{3}$ All data transformed to logarithms (base 10). Data sources: Harvey and Clutton-Brock (1985) and Smith (1989a).

${ }^{2}$ Female body weight; male body weight gives nearly identical results.

${ }^{3}$ Partial correlations of life history variables with brain weight after correction for body weight are, respectively, $0.39,0.40,0.54,0.32$, and 0.90 .

$0.66-0.91)$, as it is with brain weight ( $r=$ $0.71-0.98)$.

The multiple correlation is also included in Table 2 from a model attempting to explain each life history variable with both brain and body weights. Multiple correlations show only marginal gains, if any, in explained variation when both brain and body weight are combined as independent variables. Brain weight alone is a powerful independent variable in explaining life history. Sacher himself argued strongly that brain weight is the key independent variable and that brain metabolism and brain energetics comprise the pacemaker of vertebrate growth and aging (Sacher and Staffeldt, 1974:604; see also Hofman, 1983). Indeed, after correction for the effect of body weight, the partial correlation between age of emergence of $M_{1}$ and brain weight in primates remains $r=0.90$, suggesting that this association rises above the effect due to body weight alone. For present purposes it is not necessary to insist on causality; it suffices to say that measures of size are highly correlated with measures of development across primate species. The strongest evidence for an effect of size on life history is given by the correlation of brain weight with age of emergence of $\mathrm{M}_{1}$ of $r=0.98$.

Figure 2 illustrates the tightness of the relationship between brain weight and age of first molar emergence. As might be expected, the smallest brain and the earliest emergence time belong to the tiny $(180 \mathrm{gm})$ primate Cheirogaleus medius. However, the largest brain and the longest time to $M_{1}$ emergence belong to Homo sapiens rather than to the larger-bodied gorilla. No species is particularly aberrant, although Propithecus verreauxi shows the largest residual; this species represents the sole datum for tooth emergence that is based on multiple observations of a single subject (other prosimian data are based on 5-13 subjects per species; see Eaglen [1985]). In contrast, data for anthropoids are based on substantial numbers of subjects (see original sources as given by Smith [1989a]). The strength of the relationship is all the more remarkable given the variety of sources for these data.

Relationships between size and life history in living primate species can be used to make predictions for extinct hominid species, for which we can estimate brain and body weight from the fossil record (Table 3 ). Only the 15 anthropoid species have been used in calculating prediction equations in order to minimize error for higher primates and because of the far greater sample size in anthropoid studies. Both brain and body weights are used to predict life history; however, the body weight coefficient is relatively small (see Table 4). Thus altering body weight estimates for hominid species has a minor effect on predictions.

In Table 4, two aspects of life history are predicted: age of emergence of $M_{1}$ and life span. Life span is included particularly because its significance is more easily grasped than is that of tooth emergence; in this context it should be regarded as a constitutional characteristic of a species, an achievable span under good conditions. ${ }^{1}$ In any case, it

\footnotetext{
${ }^{1}$ In strict terminology (Sacher, 1959), life span indicates maximum value reported. However, Harvey and Clutton-Brock (1985) give moderate values for "life span," e.g., human life span is entered as 70 years rather than 90 or 100 , and chimpanzee life span appears as 45 rather than 55 years. Technically these are "life expectancy" at a percentile that has not been specified.
} 


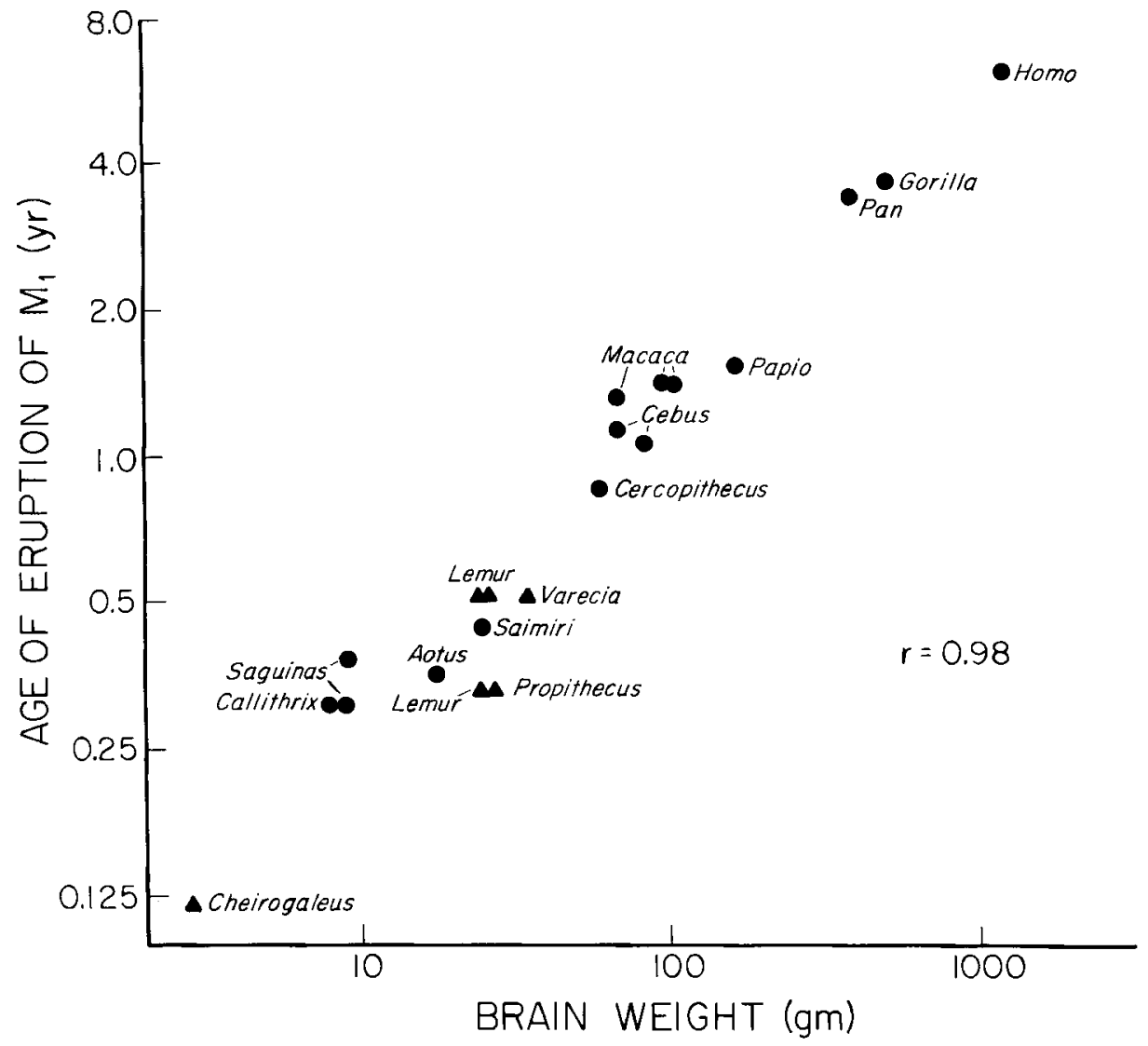

Fig. 2. Relationship between age of eruption of the mandibular first molar and brain weight in 21 primate species (within 15 labeled genera): circles, anthropoids; triangles, prosimians. The log-log plot shows proportional relations as brain weight goes from $3 \mathrm{gm}$ to $>1,200 \mathrm{gm}$ and age of $M_{1}$ eruption spans 6 weeks to 6

is the predicted change in life span across species that is most important.

Table 4 describes predictions for fossil hominids in three grades. In grade I, both "robust" and "gracile" australopithecines are predicted to erupt first molars at 3-3.5 years, with a life span on the order of 35-40 years. This describes a life history essentially like that of a chimpanzee. In grade II, an intermediate life history is predicted to characterize early Homo. Homo habilis and early Homo erectus are predicted to erupt $\mathrm{M}_{1}$ at $4-4.5$ years, with a potential life span ranging near 50 years. Approach to a modern grade of life history is expected to begin with later $H$. erectus, as average brain size crests years. As shown, brain weight is an excellent predictor of dental maturation: $r=0.98$ for all species and $r=0.99$ for anthropoids only. Species list and sources for dental data are given in Smith (1989a); brain weights are from Harvey and Clutton-Brock (1985).

1,000 cubic centimeters. At this point, predicted eruption of $\mathrm{M}_{1}$ nears known human means of $\sim 5.5-6+$ years (Dahlberg and Menegaz-Bock, 1958); predicted life span reaches into the sixties. Predictions for human dental maturation and life span from these equations are reasonable whether based on small $(40 \mathrm{~kg}, 1250 \mathrm{cc})$ or average (50 $\mathrm{kg}, 1370 \mathrm{cc}$ ) size estimates. ${ }^{2}$

\footnotetext{
${ }^{2}$ If living humans are not presently on the prediction line, then it becomes less convincing that immediate ancestors were on the line; if neither humans nor chimpanzees fall close to a prediction line, few would be convinced that extinct species linking the two belong on it. Gelvin and Albrecht (1989) pointed out that a problem in discussions of gestation length in Neanderthals (Trinkaus, 1984) was that modern humans were not well described by the equations used for Neanderthals.
} 
TABLE 3. Estimates of brain weight and body weight for hominid species

\begin{tabular}{lll}
\hline Taxon & $\begin{array}{c}\text { Female body } \\
\text { weight }(\mathrm{kg})\end{array}$ & $\begin{array}{c}\text { Cranial } \\
\text { capacity (cc) }\end{array}$ \\
\hline Homo & & \\
H. s. sapiens & $40,50^{1}$ & $1,250,1,370^{1}$ \\
H. s. neanderthalensis & 50 & $1,470^{2}$ \\
Late H. erectus & 40 & $1,060^{3}$ \\
Early H. erectus & 40 & $810^{3}$ \\
H. habilis & 35 & $642^{4}$ \\
Australopithecus & & \\
A. robustus $/$ boisei & 40 & $500^{4}$ \\
A. africanus & 30 & $442^{4}$ \\
A. afarensis & 30 & $400^{5}$ \\
\hline
\end{tabular}

'Note two sets of values. Female body weight estimates used here are on the low side to maintain consistency with prediction equations based on Harvey and Clutton-Brock (1985) data. These authors represent extant humans with small values $(40 \mathrm{~kg}$ and $1,250 \mathrm{cc}$ ); these appear in correlation analyses and prediction equation. A value of $1,370 \mathrm{cc}$ (Tobias, 1971) and $50 \mathrm{~kg}$ should better represent average values for modern humans. Both sets are used to generate predictions in Table 4. See McHenry (1988) and Jungers (1988) for discussion of hominid body weight.

'Tobias (1971).

Wolpoff (1984).

'Holloway (1970).

${ }^{5}$ Holloway (1983) cited in Falk (1985).

The strong relationship between size and life history in living primates comprises a strong line of evidence on the evolution of life history in hominids. At the same time it is a hypothesis that early hominids follow such predictions. Thus the next step in this investigation is to look at the fossil record itself.

\section{THE FOSSIL RECORD \\ Incremental lines}

Many techniques exist to estimate age of a mammalian subject (see Kimura, 1977). A variety of animal tissues grow in increments that are related to the external "clocks" of astronomical cycles (Neville, 1967; Dean, $1987 \mathrm{~b}$ ). There is a substantial and growing body of experimental and historical evidence that growth of tooth enamel and dentin follows external clocks with a reliability that is high enough to allow fairly precise estimates of time elapsed during formation of crowns of teeth (Gysi, 1931; Schour and Poncher, 1937; Okada, 1943; Fukuhara, 1959; Klevezal and Kleinenberg, 1969; Yilmaz et al., 1977; Scheffer and Myrick, 1980; Fisher, 1987; Hohn et al., 1989; Koch et al., 1989; Bromage, this volume; Dean and Beynon, this volume). It is usual to section teeth in order to count lines and bands of incremental growth, a requirement that has limited application of these methods in the case of hominid fossils. Recently, Bromage and
TABLE 4. Predicted age of eruption of mandibular $M_{1}$ and life span for the Hominidae based on equations relating life history to brain and body weight in living anthropoid primates

\begin{tabular}{llc}
\hline & \multicolumn{2}{c}{ Predicted age (years) } \\
\cline { 2 - 3 } Taxon & $\mathrm{M}_{1}$ eruption $^{1}$ & Life span \\
\hline III. Later Homo \\
$\quad$ H. s. sapiens & $5.9,6.3$ & 66 \\
$\quad$ H. s. neanderthalensis & 6.6 & 69 \\
$\quad$ Late H. erectus & 5.4 & 60 \\
II. Early Homo & & \\
$\quad$ Early H. erectus & 4.6 & 52 \\
$\quad$ H. habilis & 4.0 & 47 \\
I. Australopithecus & & 40 \\
A. robustus/boisei & 3.4 & 39 \\
A. africanus & 3.2 & 37 \\
A. afarensis & 3.0 & - \\
\hline
\end{tabular}

'Prediction equation based on $\mathbf{N}=15$ anthropoid species, multiple $r=0.99: \log \mathbf{M}_{1}$ eruption age year $=0.59419(\log$ brain weight $\mathrm{gm})+$ 0.010179 ( $\log$ female body weight $\mathrm{kg}$ ) -1.0826 .

${ }^{2}$ Prediction equation based on $\mathrm{N}=36$ anthropoid species, multiple $r=0.85$ : $\log$ life span year $=0.55896(\log$ brain weight $\mathrm{gm})-0.20999$ (log female body weight $\mathrm{kg})+0.42528$.

Dean (1985) pointed out that enamel perikymata, growth increments visible on the surface of well-preserved and unworn human incisor crowns, can be seen also in fossil hominids, although they are only poorly visible on pongid incisors (Dean, 1987b). These surface markings provide a nondestructive means of estimating time.

The purpose of counting time passed during formation of a single tooth crown is to find the age of occurrence of some other developmental event. Of particular interest, incisor perikymata have been used to estimate age of death for three australopithecines who died at or very near the time of emergence of $M_{1}$ through the gingiva: SK 63 (Swartkrans) (see Fig. 3), STS 24 (Sterkfontein), and LH 2 (Laetoli hominid). Bromage and Dean (1985) determined that incisor crowns of these three australopithecines (Table 5) formed during 2.1-3.1 years, an amount somewhat less than the 4.2 years estimated from a control sample of modern human incisors. To estimate age at death, an additional 3-4 months must be added to represent time elapsed before calcification begins (known to be shortly after birth in hominoids), and time must be added for the slight amount of root formation begun in each specimen. Resulting estimates of age at death based on perikymata come far closer to 3 years of age than to the 6 years of age expected if emergence followed a human time scale. Estimates of 3.2-3.3 years of age 


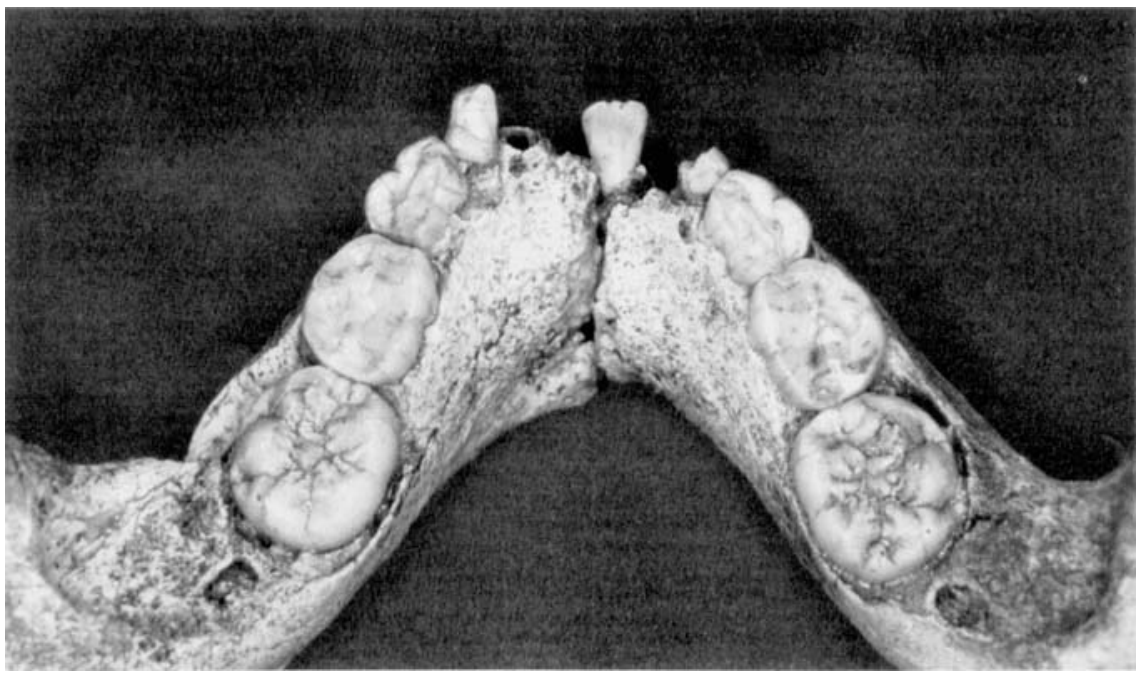

Fig. 3. Mandibular dentition of SK 63 (A. robustus from Swartkrans), for which age at death has been determined as 3.2 years by incremental lines in the permanent incisor (Bromage and Dean, 1985). Age of death also dates emergence of the first permanent molar because $M_{1}$ is caught mideruption: the tooth is not yet fully at occlusal level, and bone margins surrounding the crown are still expanded. Tiny wear facets on cusp tips confirm that the tooth had barely cut the gingiva, satisfying the precise definition of "tooth emergence" used in studies of living children. for the three specimens are within the envelope of ages predicted for australopithecine $\mathrm{M}_{1}$ emergence based on brain and body weights presented in Table 4 (ages 3.0-3.4). These ages match that expected for a chimpanzee erupting its $\mathrm{M}_{1}$ (3.3 years [Nissen and Riesen, 1964]), differing markedly from that typical in humans (5.5-6 years [Dah]berg and Menegaz-Bock, 1958]).

Based on their results, Bromage and Dean (1985) also suggested that early Homo matured as rapidly as Australopithecus. However, there is a difference between available samples of the two genera that allows some room for questions on this point. At present there is no early Homo material known from individuals who died near the time of $\mathrm{M}_{1}$ emergence; all juveniles identified thus far are developmentally older. Incisor perikymata are best used to calibrate growth events that occur while incisor crowns are still growing or shortly after their completion (Dean, 1987b:162). For hominoids, this should cover a period shortly after birth to $\sim 4$ years of age (see Dean and Wood, 1981). Older juveniles become problematic because time elapsed between completion of crown and death must be estimated more grossly, by comparing root length with average schedules for root formation in extant great apes or humans. Nondestructive techniques are not yet available to estimate precisely time elapsed during subsequent root formation or of crown formation of later forming teeth by counts of growth increments (but see Dean [1985b] and Beynon and Wood [1987]). The result is that the proportion of age at death that has been counted in lines and bands decreases for specimens over ages 3-4 years. For STS 24 and LH 2 (Table 5), more than $90 \%$ of total assigned age has been counted in tooth crown perikymata as opposed to estimated from average schedules of root formation (see Table 1 of Bromage and Dean, 1985); for SK 63 this amount is reduced to $68 \%$ because of the shorter time of crown formation in robust australopithecines. In contrast, for KNM-ER 820 , the early Homo specimen considered by Bromage and Dean (1985), only $47 \%$ of the assigned age of 5.3 years is based on incremental line count. Thus a test of the developmental schedule of early Homo comparable in precision to that for the australopithecines in Table 5 awaits recovery of a younger individual, especially one with a newly emerging $M_{1}$. Such a specimen might be recovered at any time, allowing a test of 
TABLE 5. Age assigned to three juveniles of Australopithecus who died at or shortly after emergence of the mandibular first molar ${ }^{1}$

\begin{tabular}{|c|c|c|c|}
\hline \multirow[b]{3}{*}{$\begin{array}{l}\text { Taxon, site, and } \\
\text { specimen }\end{array}$} & \multicolumn{3}{|c|}{ Age (years) } \\
\hline & \multicolumn{2}{|c|}{ Bromage and Dean (1985) } & \multirow{2}{*}{$\begin{array}{c}\text { Mann et al. (1987) } \\
\begin{array}{l}\text { Age of death } \\
\text { from human } \\
\text { eruption schedule }\end{array}\end{array}$} \\
\hline & $\begin{array}{c}\text { Time counted } \\
\text { for perikymata } \\
\text { formation on I1 }\end{array}$ & $\begin{array}{c}\text { Age of death } \\
\text { (I1 crown formation } \\
\text { plus lapsed time) }\end{array}$ & \\
\hline \multicolumn{4}{|l|}{ A. robustus } \\
\hline $\begin{array}{l}\text { Swartkrans } 63 \\
\text { A. africanus }\end{array}$ & 2.15 & 3.2 & $6-7$ \\
\hline Sterkfontein 24 & 3.09 & 3.3 & $5-6$ \\
\hline A. afarensis & & & \\
\hline Laetoli hominid 2 & 3.00 & 3.3 & $5-6$ \\
\hline
\end{tabular}

${ }^{1}$ Results from incremental line studies (Bromage and Dean, 1985) compared with traditional estimates (Mann et al., 1987).

${ }^{2}$ Time counted for perikymata (column 1) divided by age of death (column 2) gives a measure of precision for incremental line-based ages of death because time lapsed before and after crown formation must be estimated by more approximate schedules; for these specimens this proportion is $0.68,0.94$, and 0.92 , respectively.

the predicted age of emergence of $M_{1}$ of $\sim 4.5$ years.

\section{Developmental sequences}

Whatever the specific data employed, growth and development of an extinct species is evaluated by comparing two or more growth events observed in the fossil with those expected from a model, usually a living species. At a basic level, the comparison above based on incremental lines is a comparison of physiological age based on one tissue or growth process (I1 enamel perikymata) with that derived from another (eruption of $M_{1}$ ). Counts of growth increments may give more precise or more reliable age estimates than those based on other aspects of tissue aging, but in principle their study is not fundamentally different from study of a sequence or pattern of growth events (e.g., Smith, 1986). ${ }^{3}$ Other types of comparison of developmental sequences can be investigated that make use of a larger sample of fossil hominids, albeit at a lower level of precision than that available with lines of incremental growth.

Data on sequence or pattern of tooth crown and root development can be gleaned from radiographs, CT scans, or simply from the jaws of juveniles that are broken open. Such material can be observed to assess proportion of crowns and roots that have completed formation for each tooth (Koski and Garn, 1957; Mann, 1975; Skinner and Sperber,

\footnotetext{
${ }^{3}$ Ages based on incremental lines are physiological ages rather than "absolute" or "chronological" ages, because growth rhythms are responses to physiological conditions, not direct responses to sidereal time.
}

1982; Smith, 1986, 1989b; Bromage, 1987; Conroy and Vannier, 1987; Dean, 1985a, 1987a; Conroy, 1988). Resulting data are in principle no different from those obtainable from a growth record of a living child, with the limitation that data are cross-sectional.

In evaluating an extinct species, it is appropriate to ask whether growth events observable are consistent with those expected in a living model. Weidenreich (1937), Clark (1947), Dart (1948a,b), Senyurek (1955), and Mann (1975) all realized the appropriateness of comparing dental development of fossil hominids to that of extant humans and great apes, and all made descriptive observations to this end. At present sufficient data have accumulated to allow numerical treatment of the same comparisons. A simple numerical allocation of fossil specimens into dichotomous categories "like humans" or "like apes" has heuristic value (Smith, 1986); however, other techniques are required to recognize intermediate or unique states.

One way to assess similarity of an individual to a reference population is with a pattern profile (Fig. 4). Pattern profiles provide a simple and easily grasped description of basic data that is multivariate rather than pairwise and also compares data to a reference population (Garn et al., 1968). In Figure 4 , stages of dental development of three subjects have been plotted on a summary chart of human dental development using the methods of Smith (1986). ${ }^{4}$ The degree to

\footnotetext{
${ }^{4}$ Note that the following analysis makes use of human standards of dental development as in Smith (1986), but differs from that work in making no use of standards for great apes.
} 


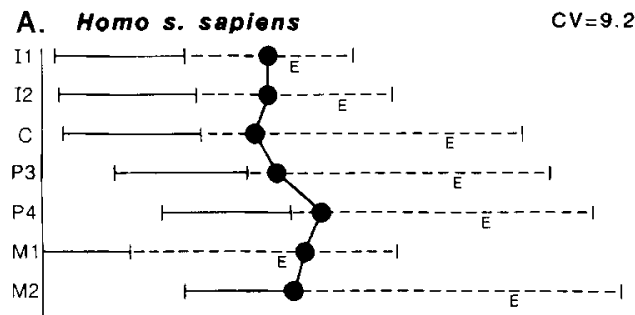

B. Homo erectus

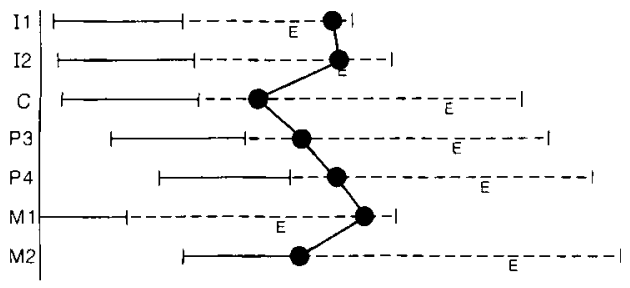

C. Pan troglodytes

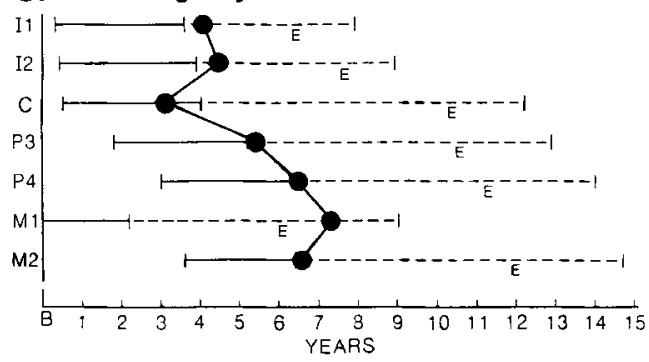

Fig. 4. Pattern profiles of dental development of three individuals (A-C) with complete data I1-M2. Third molars omitted because there are no data on these teeth for any fossil hominid considered here. Stages of tooth formation are plotted following Smith (1986) on a summary representation of human dental development (normative standards based on 345 normal American children from Moorrees et al. [1963]; chart modified from Dean and Wood [1981]). Solid lines represent the period of crown formation; dashed lines, root formation; and "E," emergence of teeth through the gingiva. The associated human dental age is provided by a scale in years. Note that fit to a straight line (an indication of consistency with standards) becomes worse from $\mathrm{A}$ to $\mathrm{C}$, from $H$. s. sapiens (Van der Linden-14 in Table 6), to H. erectus (KNM-ER 820), to Pan troglodytes (BMNH 1939 998), this is also expressed by the coefficient of variation of dental ages (CV) increasing from 9.2 to 28.5. Note that the pattern of deviation shown in $B$ appears magnified in $\mathrm{C}$.

which the plotted points form a straight line expresses the fit of the individual to expectations based on the reference population. The choice of the reference population is arbitrary in principle, although in practice it is dictated by quality of available data (Smith, 1987, 1991b). None of the analyses below requires that the standard chosen describes all living human populations.

Great apes, gracile australopithecines, and some members of Homo share an "Sshaped" pattern when graphed on human standards (Smith, 1986), as illustrated for Pan and $H$. erectus in Figure $4 \mathrm{~B}$ and $\mathrm{C}$. Specifically, I1 through P3 appear delayed in formation relative to the first molar. This pattern has been interpreted (Smith, 1986) as a shared primitive pattern of development.

Although the shape of profiles is of interest (see Smith, 1986, 1989b, for a more complete discussion), here the primary focus is degree of deviation from the reference population. Following Garn et al. (1985), the variation of a pattern profile from a normative standard (also a measure of distance from a standard) can be expressed by the variance within a set of scores. In this case, dental ages are the scores; their variance is expressed as the coefficient of variation because variance is highly dependent on mean dental age (see Moorrees et al., 1963).

In Figure 4, the human child at top (A) fits standards fairly well. Dental ages assessed for individual teeth of this subject ranged from 5.5 to 7.1 years, giving a CV of 9.2 . Below appear more deviant patterns, ones that result when dental development of a fossil hominid (B) and a chimpanzee (C) are plotted on human standards. The greatest lack of consistency with these human standards is shown by the chimpanzee, as reflected in dental ages that range widely for different teeth, from 3.1 to 7.3 years, giving a $\mathrm{CV}$ of 28.6, i.e., the chimpanzee makes a comparatively poor human in terms of dental development.

In Table 6, comparison of CV of dental age is extended to samples of recent humans, hominid fossils, and recent great apes, for a total of 28 individuals. Ideally, CV of dental age should be calculated over precisely the same teeth before comparing cases. Here, CV is calculated for the teeth I1-M2 when data are present for at least six of these seven teeth with all fields of the dentition (incisor, canine, premolar, molar) represented; missing data were allowed for either one incisor or one premolar. This necessary stricture standardizes comparisons, but it narrows num. ber of available subjects.

Two of the human subjects in Table 6 , "Van der Linden-14" and "Hasanlu 73-5-58" (unshaded, unlettered boxes in Fig. 5, top), were chosen by Mann and associates for 
TABLE 6. Distance from standards of human mandibular tooth development expressed as the coefficient of variation of dental age (scored by an arbitrary human standard) for samples of modern humans, fossil hominids, and great apes ${ }^{1}$

\begin{tabular}{lcc} 
& \multicolumn{2}{c}{ CV of dental age } \\
\cline { 3 - 3 } Site/specimen 2,3 & Mandible & Maxilla \\
\hline Homo sapiens & & \\
Canadian A & 12.3 & - \\
Canadian B & 9.7 & - \\
Canadian C & 5.5 & - \\
Canadian D & 10.3 & - \\
Inuit In-2 & 7.7 & - \\
Iraq & 6.9 & - \\
Iran (Hasanlu 73-5-58) & - & 16.0 \\
Van der Linden-14 & - & 9.2 \\
Gibraltar 2 Neanderthal & 11.4 & - \\
Homo erectus & & \\
Zhoukoudian B-I & 14.6 & - \\
KNM-ER 820 & 12.5 & - \\
Homo habilis & & \\
KNM-ER 1590 & - & 23.8 \\
Robust Australopithecus & & \\
KNM-ER 1820 & 16.2 & - \\
SK 63 & 17.1 & - \\
SK 61 & 9.9 & - \\
Gracile Australopithecus & & - \\
STS 245 & - & - \\
STW 151 & 20.3 & -2.8 \\
Taung & 25.0 & - \\
LH 3 & - & - \\
Pan troglodytes & 21.3 & - \\
PFA P & 22.4 & - \\
PFA M & 25.7 & - \\
PFA C & 31.4 & - \\
HPM N7558 & 28.3 & - \\
PCM M635 & 25.1 & - \\
PCM M644 & 28.6 & - \\
BMNH 1939 998 & 36.0 & - \\
BMNH 1948 3221 & & - \\
Pongo pygmaeus & & - \\
HPM N3479 & & - \\
\hline
\end{tabular}

${ }^{1}$ Calculated for specimens with at least six teeth I1-M2 and all fields of the dentition represented.

${ }^{2}$ Raw data and sources for specimens given in Smith (1989b), except the last four specimens of Pan (unpublished data)

KNM, Kenya National Museum; PFA, Primate Foundation of Arizona: PCM. Powell Cotton Museum; HPM, Harvard Peabody Museum; BMNH, British Museum (Natural History).

${ }^{4}$ Raw data corrected from Smith (1989b) after discovering additional views in Weidenreich $(1936,1937)$.

${ }^{5}$ Dental age for a critical tooth $\left(\mathbf{M}^{1}\right)$ based on emergence rather than root formation; this may inflate CV. Age of KNM-ER $820 \mathrm{I}_{2}$ also based on emergence.

perceived similarity to fossil specimens. Indeed, Mann (1988) and Mann et al. (1987, 1990 ) base their claim that dental development of gracile Australopithecus and $H$. habilis fits easily with modern humans on these two specimens. Developmental stages of Van der Linden-14 were said to show "nearly precise overlap" with those of KNMER 1590 (Mann et al., 1987), and those of Hasanlu 73-5-58 were said to be "parallel to" Taung (Mann, 1988). The CVs of these hu- mans (9.2 and 16.0) are considerably less than those of KNM-ER 1590 (23.8) and Taung (25.0). In contradiction to Mann and associates, the cases do not match the fossils, their pattern profiles distinguish them as humans, and the dichotomous allocation procedures of Smith $(1986,1989 \mathrm{~b})$ correctly sort them as humans, not apes (demonstrated in Smith 1989b).

Figure 5 presents the data of Table 6 graphically for successive samples of great apes, gracile Australopithecus, and Homo. It is evident that values for the maxilla (unshaded blocks) are shifted to the right compared with those for the mandible (shaded), a reasonable finding since $\mathrm{CV}$ is calculated as the deviation from standards of mandibular development. At top, the Neanderthal child (Gibraltar 2) is easily subsumed in the distribution of $H$. sapiens, which itself is centered around a value of $\sim 10$. At bottom, it can be seen that great apes develop much higher CVs when development is scored' by a human standard, with values ranging between 20 and 35. Gracile Australopithecus from Sterkfontein, Taung, and Laetoli overlaps with great ape in degree of deviation from human standards. Of most interest, early Homo appears to make up an intermediate distribution, spanning those of Australopithecus and $H$. sapiens.

Each distribution in Figure 5 overlaps with the next, but the important point is that they have entirely different central tendencies. Even with these small samples it is possible to show by median tests that the $H$. sapiens distribution is significantly different from that of Pan $(P<0.0001)$ and that of Australopithecus $(P<0.02)$. Distributions of Pan and Australopithecus cannot be distinguished statistically, although Figure 5 hints that the two may differ slightly. It will be interesting to reassess this comparison as more data become available. With its small sample and intermediate values, the early Homo distribution cannot yet be distinguished from any other distribution statistically. Overall, Figure 5 shows that developmental sequences appear to become more consistent with those of modern $H$. sapiens from Australopithecus to early Homo to H.s. neanderthalensis.

Robust australopithecines (Tables 6, 7) have proved more difficult to understand. There is long-standing debate as to whether they share some special features of human dental development (Broom and Robinson, 1951; Mann, 1975; Dean, 1985a; Smith, 


\section{DISTANCE FROM HUMAN STANDARDS}
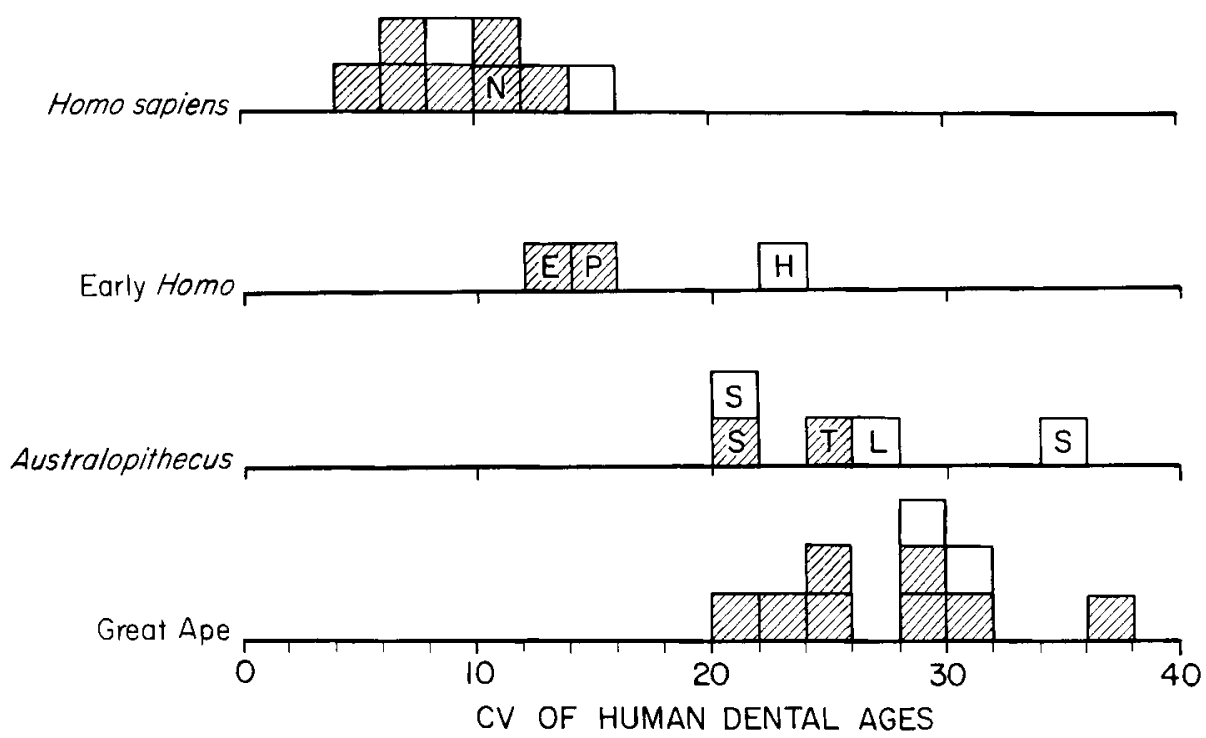

Fig. 5. Distance from human standards for development of mandibular teeth in successive samples of humans, fossil hominids (letters), and great apes (Pan, Pongo); data from Table 6. Each box represents the CV of human dental age for a single individual: shaded boxes, mandibles; unshaded boxes, maxillae. Fossil hominids: $\mathrm{N}$, Neanderthal; E, early African $H$. erectus (H. e. er-

1986; Grine, 1987; Conroy, 1988). Indeed, the dichotomous allocation procedure used previously (Smith, 1986, 1989b) classed "robusts" as "humanlike" versus "apelike" quite consistently. This is puzzling given the enormous amount of other information about robusts indicating that the group is a side branch of human evolution (e.g., 'Tobias, 1967; Grine, 1988). Analysis of robust australopithecines is hampered by the extreme youth of most of the available sample (first molar development indicates $\leqslant 3$ years of age by either great ape or human standards [Smith, 1989b]) and the paucity of specimens with complete data for I1-M2. Smith (1986, $1989 \mathrm{~b})$ has suggested, based on the advanced development of anterior teeth relative to the first molar, that robusts show a unique condition in terms of dental development. In terms of CV of dental age, robust australopithecines apear to be more distant from human samples and human standards than early Homo, but closer than gracile Australopithecus (Table 6). gaster); $\mathrm{P}$, late $H$. erectus (H.e. pekinensis); $\mathrm{H}, H$. habilis. Gracile Australopithecus given by localities: S, Sterkfontein; T, Taung; and L, Laetoli. Note that gracile Australopithecus nears great apes in degree of deviation from these human standards. Later fossils hominids are more similar to samples of humans and to reference standards.

In Table 7, particular attention is given to the effect of canine data on comparisons. Canine development forms a striking difference between humans and most other primates. Compared with humans, anthropoid primates have large sexually dimorphic canine teeth that show protracted development and late emergence (Schultz, 1935; Dean and Wood, 1981; Swindler et al., 1982). If resemblances in developmental sequence are controlled by canine development, the case for the importance of these sequences is weakened, i.e., evolutionary trends from Australopithecus through Homo could reflect only a lessening of sexual dimorphism in canine teeth rather than change of broader significance. To investigate the effect of the canine, Table 7 compares CV and median CV of human dental age (for cases presented in Table 6) calculated both with and without the canine tooth.

Table 7 shows that CV changes for some groups but not for others when canine data are omitted. Those with the "primitive pat- 
TABLE 7. Coefficient of variation of human dental age compared for samples in Table 6 computed with and without data for the canine

\begin{tabular}{|c|c|c|c|c|}
\hline \multirow[b]{2}{*}{ Taxon } & \multicolumn{2}{|c|}{ CV canine included } & \multicolumn{2}{|c|}{ CV canine omitted } \\
\hline & Raw data & $\operatorname{Median}^{1}$ & Raw data & Median $^{2}$ \\
\hline \multicolumn{5}{|l|}{ Homo sapiens } \\
\hline & $\begin{array}{l}12.3,9.7,5.5 \\
10.3,7.7,6.9 \\
16.0,9.2,11.4\end{array}$ & 9.7 & $\begin{array}{l}12.9,9.9,5.1 \\
11.0,4.7,4.2 \\
16.7,8.4,12.4\end{array}$ & 9.9 \\
\hline Early Homo & & & & \\
\hline Robust Australopithecus & 14.6, 12.5, 23.8: & 14.6 & 14.0, 8.4, 14.1: & 14.0 \\
\hline Gracile Australopithecus & $16.2,17.1,9.9$ & 16.2 & $17.3,14.9,9.5:$ & 14.9 \\
\hline 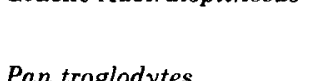 & $\begin{array}{l}35.8,20.3,20.6 \\
25.0,26.2:\end{array}$ & 25.0 & $\begin{array}{l}27.3,14.0,13.0 \\
22.3,20.9\end{array}$ & 20.9 \\
\hline Fan erogidaytes & $\begin{array}{l}21.3,22.4,25.7 \\
31.4,31.9,28.3 \\
25.1,28.6,36.0\end{array}$ & 28.3 & $\begin{array}{l}14.9,12.9,13.8 \\
22.3,20.3,21.9 \\
18.1,22.2,29.5\end{array}$ & 18.1 \\
\hline Pongo pygmaeus & 28.3 & & 15.9 & \\
\hline
\end{tabular}

${ }^{1}$ Group medians significantly different by Kruskal-Wallis test at $P<0.0001$. In pairwise median tests $H$. sapiens differs from gracile Australopithecus at $P<0.02$ and from $P a n$ at $P<0.0001$; other comparisons not significant.

${ }^{2}$ Group medians significantly different by Kruskal-Wallis test at $P<0.005$. In pairwise median tests $H$. sapiens differs from gracile Australopithecus at $P<0.02$ and from $P a n$ at $P<0.0001$; other comparisons not significant.

tern" of development strongly expressed (great apes and gracile Australopithecus) show substantial reductions in median CV, amounting to a drop of 5-10 points. However, this procedure has little or no effect on CV for robusts or Homo. Apparently, the canine is not a special contributor to variance in robusts or Homo, and this shared attribute may account for some of their perceived similarity in previous analyses (e.g., Smith, 1986). The single specimen of $H$. habilis (KNM-ER 1590) is grouped here with $H$. erectus, although it may indeed show a more strongly primitive pattern (Smith, 1991c). Without the canine, its CV drops from 23.8 to 14.1 , lessening its apparent distance from $H$. erectus. Dropping canine data also halves the distance between robust and gracile australopithecines, creating overlap between individuals in the two groups. Lastly, it slightly lessens the distance between gracile Australopithecus and Pan. Statistical significance is little affected, and great apes and gracile australopithecines still diverge from the reference population by amounts that are approximately equal to each other. Results in Table 7 help to make two points: 1) A CV of 14 might appear for a single individual of any hominoid species (canine data omitted); nevertheless, distributions of CVs demonstrate clear species differences. 2) The maintenance of distinctions between humans, gracile australopithecines, and great apes when the canine is omitted suggests that differences in dental development among these groups are broadly based, not merely the product of resemblances in one or two teeth. Indeed, regardless of analytical technique (above, Smith, 1986, 1989b, 1991c; Simpson et al., 1990), developmental sequences of earliest fossil hominids resemble those of living apes and sequences of more recent fossil hominids approach living humans.

\section{SUMMARY AND CONCLUSION}

The combination of newly available information and a multiplicity of new approaches has advanced our understanding of the development of the hominoid dentition, and this knowledge is applicable to problems in the evolution of human growth and development. Dental development is strongly and critically integrated into somatic growth and life cycle in primates and other mammals. This proposition can be defended on numerous grounds (Schultz, 1935, 1960, 1969; Mann, 1975; Pond, 1977; Shigehara, 1980; Swindler et al., 1982; Smith, 1991a), but it is supported explicitly by the strong correlation of markers of dental development with an array of life history measures in living 


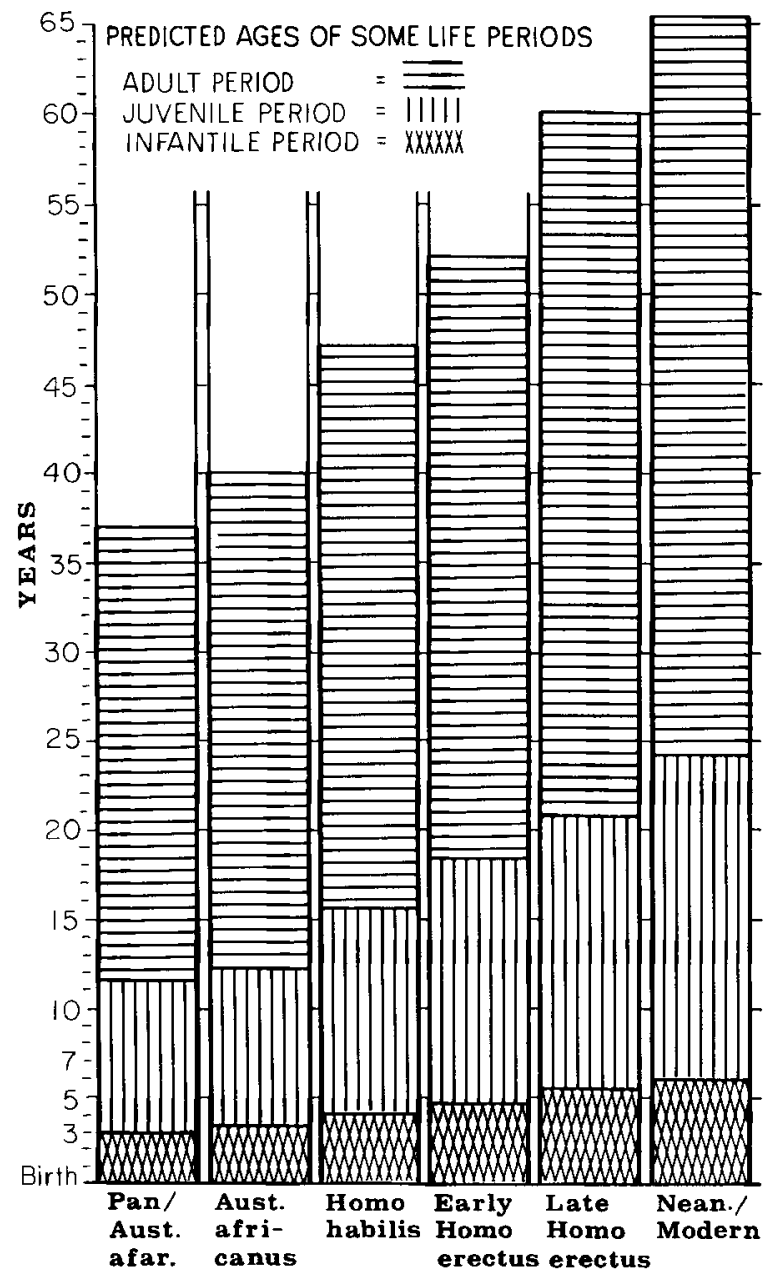

Fig. 6. Evolution of infancy, the juvenile period, adulthood, and longevity in Hominidae as predicted from brain and body weight estimates for fossil species, drawn in the style of Schultz (1960). Pan included to suggest equivalency with $A$. afarensis. Age of emergence of the first permanent tooth (end of infancy), completion of permanent dentition (end of the juvenile period), and life span, respectively, predicted from the independent variables brain and body weight in equations developed from extant anthropoids. Over the 3 million or more years of evolution represented here, length of infancy is predicted to increase by 3 years as attainment of adulthood increases by 10 years and life span by 30 years. Future additions to primate data may refine prediction equations; at present, prediction for completion of permanent dentition is based on only 12 anthropoid species (data in Smith, 1989a); other predictions as in Table 3. primates (Smith, 1989a). Three lines of evidence concerning the dentition have emerged recently that speak to the evolution of life history in the Hominidae.

1. Extensive data on living primates support the general proposition that mammalian growth and aging are highly related to the morphological attributes brain weight and body weight (Sacher, 1959; Sacher and
Staffeldt, 1974; Harvey and Clutton-Brock, 1985). This is most strongly shown by the correlation of age of $M_{1}$ emergence (used as a general measure of maturation), with brain weight at $r=0.98$ in 21 species of extant primates (Smith, 1989a). Relationships between life history and size known in living primates make a clear prediction for evolution of hominid life history in light of the 
brain and body weights estimated from the fossil record. Predictions describe an apelike grade of life history for Australopithecus, an intermediate grade for early Homo, with an approach to a modern grade appearing only with later $H$. erectus, as mean brain size crests 1,000 cc. Figure 6, a reprise of Schultz's classic drawing, depicts the evolution of hominid life history based on the proposition that the best predictor of life cycle is size, in this case, brain and body size.

2. Counts of incremental lines in incisors calibrate an important event in dental maturation. Bromage and Dean (1985) determined ages of $\sim 3.25$ years for emergence of the mandibular first molar for three specimens of Australopithecus from counts of incisor perikymata, an age that would be expected in a great ape rather than a living human. Strong correlation of age of emergence of $M_{1}$ with the entire spectrum of measures of growth and development in living primates (Smith, 1989a) implies that other aspects of maturation of Australopithecus were also on a great ape grade.

3. Developmental sequences within the dentition appear to become more consistent with those of $H$. s. sapiens over several million years of hominid evolution (Smith, 1986, $1989 \mathrm{~b}$ ). An overall measure of consistency is provided by the coefficient of variation of dental age when dental age is scored according to standards based on a living human population. Great apes and australopithecines appear about equal in terms of overall divergence from the human standard; this divergence is substantial. Taken together, $H$. erectus and $H$. habilis show an intermediate degree of deviation between australopithecines and a small but diverse sample of recent humans.

I would suggest further that the particular sequences of dental development seen in gracile Australopithecus and great apes are allowed by rapid growth in the length of the face and that the slower facial growth and slower overall somatic growth that evolves later in time fundamentally changes sequences of development of anterior versus posterior teeth. This explanation follows Schultz (1960) and differs from Simpson et al. (1990).

These new approaches are not without complexities: Relationships between size and life history beg further questions (Harvey and Read, 1988); older juveniles remain problematical for nondestructive study of incremental lines; robust australop- ithecines are puzzling in some aspects of developmental sequence. Investigations into all these areas are warranted, and additions to sample size are in order. Although much remains to be accomplished, recent evidence begins to form a coherent whole.

The three lines of evidence reviewed here agree that the unique rate and pattern of human development are not of ancient origin. This evidence suggests that small-brained, small-bodied Australopithecus possessed a life history broadly similar to that of the great apes and that life history of early Homo matched no living primate species. New evidence on life history joins a growing body of opinion (Stern and Susman, 1983; Falk, 1985; Binford, 1987; Potts, 1988; Simons, 1989) that australopithecines represent a substantially primitive grade of evolution within the Hominidae. Far from the idea that evolution of growth and aging ended in Pliocene Australopithecus (Mann, 1975; Lovejoy, 1981), I suggest that a synergism of evolving life history and increasing complexity of behavior continued to operate throughout the evolution of the genus Homo.

\section{ACKNOWLEDGMENTS}

I thank D.R. Swindler and L.A. Winkler for inviting me to participate in this symposium on primate tooth formation. I thank the governments of Kenya and Tanzania, R.E.F. and M.G. Leakey at the Kenya National Museum; P.V. Tobias and R.J. Clarke at the University of the Witwatersrand; C.K. Brain, E. Vrba, and A. Turner at the Transvaal Museum; P. Andrews and C. Stringer at the British Museum (Natural History); M.C. Dean at University College London; C.F. Merbs at Arizona State University; D.R. Pilbeam at Harvard University; and the Primate Foundation of Arizona for permission to study original material in their care. The Primate Information Center of Seattle, Washington, provided a literature search on primate dental development. I thank A.D. Beynon and P.D. Gingerich for comments on the manuscript and G. Eck for suggesting reanalysis omitting the canine. Teryl Lynn drew Figures $1,2,5$, and 6 . This research is supported by grant BNS-8717738 and BNS9020974 from the U.S. National Science Foundation.

\section{LITERATURE CITED}

Bartholomew GA, and Birdsell JB (1953) The ecology of protohominids. Am. Anthropol. 55:481-498.

Beynon $\mathrm{AD}$, and Dean MC (1987) Crown-formation time 
of a fossil hominid premolar tooth. Arch. Oral Biol. 32:773-780.

Beynon AD, and Dean MC (1988) Distinct dental development patterns in early fossil hominids. Nature 335:509-514.

Beynon AD, and Wood BA (1987) Patterns and rates of enamel growth in the molar teeth of early hominids. Nature 326:493-496.

Biggerstaff RH (1967) Time-trimmers for the Taungs child, or how old is "Australopithecus africanus"? Am. Anthropol. 69:217-220.

Binford LR (1987) American Association of Physical Anthropologists annual luncheon address, April, 1986: The hunting hypothesis, archaeological methods, and the past. Yrbk. Phys. Anthropol. 30:1-9.

Bolk L (1926) On the problem of anthropogenesis. Proc. Sec. Sci. Kon. Akad. Wetens. Amsterdam 29:465-475.

Bromage TG (1985) Taung facial remodeling: A growth and development study. In PV Tobias (ed.): Hominid Evolution: Past, Present and Future. New York: Alan R. Liss, pp. 239-245.

Bromage TG (1987) The biological and chronological maturation of early hominids. J. Hum. Evol. 16:257272.

Bromage TG, and Dean MC (1985) Re-evaluation of the age at death of immature fossil hominids. Nature 317:525-527.

Broom R, and Robinson JT (1951) Eruption of the permanent teeth in the South African fossil ape-men. Nature 167:443.

Clark WELG (1947) Observations on the anatomy of the fossil Australopithecinae. J. Anat. 83:300-333.

Conroy GC (1988) Alleged synapomorphy of the M1/I1 eruption pattern in robust australopithecines and Homo: Evidence from high-resolution computed tomography. Am. J. Phys. Anthropol. 75:487-492.

Conroy GC, and Vannier MW (1987) Dental development of the Taung skull from computerized tomography. Nature 329:625-627.

Dahlberg AA, and Menegaz-Bock RM (1958) Emergence of the permanent teeth in Pima Indian children. J. Dent. Res. 37:1123-1140.

Dart RA (1925) Australopithecus africanus: The manape of South Africa. Nature 115:195-199.

Dart RA (1948a) The adolescent mandible of Australopithecus prometheus. Am. J. Phys. Anthropol. 6:391411.

Dart RA (1948b) The infancy of Australopithecus. In AL Du Toit (ed.): Robert Broom Commemorative Volume. Cape Town: Royal Society of South Africa, pp. 143158.

Darwin CR (1871) The Descent of Man and Selection in Relation to Sex. New York: D. Appleton and Co.

Dean MC (1985a) The eruption pattern of the permanent incisors and first permanent molars in Australopithecus (Paranthropus) robustus. Am. J. Phys. Anthropol. 67:251-257

Dean MC (1985b) Variation in the developing root cone angle of the permanent mandibular teeth of modern man and certain fossil hominids. Am. J. Phys. Anthropol. 68:233-238.

Dean MC (1987a) The dental developmental status of six East African juvenile fossil hominids. J. Hum. Evol. 16:197-213

Dean MC (1987b) Growth layers and incremental markings in hard tissues; a review of the literature and some preliminary observations about enamel structure in Paranthropus boisei. J. Hum. Evol. 16:157172.
Dean MC (1989) The developing dentition and tooth structure in hominoids. Folia Primatol. 53:160-176.

Dean MC, Stringer CV, and Bromage TG (1986) Age at death of the Neanderthal child from Devil's Tower, Gibraltar and the implications for studies of general growth and development in Neanderthals. Am. J. Phys. Anthropol. 70:301-309.

Dean MC, and Wood BA (1981) Developing pongid dentition and its use for ageing individual crania in comparative cross-sectional growth studies. Folia Primatol. 36:111-127.

Dobzhansky T (1962) Mankind Evolving. New Haven: Yale University Press.

Drennan MR (1932) L'ordre d'éruption des dents permanentes chez les Boschimans. L'Anthropologie 42:491495.

Eaglen RH (1985) Behavioral correlates of tooth eruption in Madagascar lemurs. Am. J. Phys. Anthropol. 66:307-315.

Etkin W (1954) Social behavior and the evolution of man's mental faculties. Am. Nat. 88:129-142.

Eveleth PB, and Tanner JM (1976) Worldwide Variation in Human Growth. Cambridge: Cambridge University Press.

Falk D (1985) Hadar AL 162-28 endocast as evidence that brain enlargement preceded cortical reorganization in hominid evolution. Nature 313:45-47.

Fisher DC (1987) Mastodont procurement by Paleoindians of the Great Lakes region: Hunting or scavenging? In MH Nitecki and DV Nitecki (eds.): The Evolution of Human Hunting. New York: Plenum, pp. 309-421.

Fukuhara T (1959) Comparative-anatomical studies of the growth lines in the enamel of mammalian teeth. Acta Anat. Nippon. 34:322-332.

Garn SM, Koski K, and Lewis AB (1957) Problems in determining the tooth eruption sequence in fossil and modern man. Am. J. Phys. Anthropol, 15:313-331.

Garn SM, Lavelle M, and Smith BH (1985) Quantification of dysmorphogenesis: Pattern variability index. Am. J. Roentgenol. 144:365-369.

Garn SM, Lewis AB, and Blizzard RM (1965a) Endocrine factors in dental development. J. Dent. Res. 44:243248.

Garn SM, Lewis AB, and Kerewsky RS (1965b) Genetic, nutritional, and maturational correlates of dental development. J. Dent. Res. 44:228-242.

Garn SM, Lewis AB, and Walenga AJ (1968) Crown-size profile pattern comparisons of 14 human populations. Arch. Oral Biol. 13:1235-1242.

Gelvin BR, and Albrecht GH (1989) Gestation length in Neandertals, abstracted. Am. J. Phys. Anthropol. $78: 226$.

Gould SJ (1977) Ontogeny and Phylogeny. Cambridge: Belknap Press of Harvard University Press.

Grine FE (1987) On the eruption pattern of the permanent incisors and first permanent molars in Paranthropus. Am. J. Phys. Anthropol. 72:353-359.

Grine FE (1988) Evolutionary History of the "Robust" Australopithecines. New York: Aldine de Gruyter.

Gysi A (1931) Metabolism in adult enamel. Dent. Digest $37: 661-668$

Harvey PH, and Clutton-Brock TH (1985) Life history variation in primates. Evolution 39:559-581.

Harvey PH, and Read AF (1988) How and why do mammalian life histories vary? In MS Boyce (ed.): Evolution of Life Histories of Mammals: Theory and Pattern. New Haven: Yale University, pp. 213-232.

Hofman MA (1983) Energy metabolism, brain size and longevity in mammals. Q. Rev. Biol. 58:495-512. 
Hohn AA, Scott MD, Wells RS, Sweeney RS, and Irvine AB (1989) Growth layers in teeth from known-age free ranging bottlenose dolphins. Marine Mammal Sci. 5:315-342.

Holloway RL (1970) New endocranial values for australopithecines. Nature 227:119-200.

Huxley TH (1863) Man's Place in Nature. New York: D. Appleton and Co.

Issac $\mathrm{G}$ (1978) The food-sharing behavior of protohuman hominids. Sci. Am. 238 (April) 90-108.

Johanson DC, and White TD (1979) A systematic assessment of early African hominids. Science 202:321-330.

Johanson DC, White TD, and Coppens Y (1978) A new species of the genus Australopithecus (Primates: Hom. inidae) from the Pliocene of eastern Africa. Kirtlandia 28:1-14.

Jungers WL (1988) New estimates of body size in australopithecines. In FE Grine (ed.): Evolutionary History of the "Robust" Australopithecines. New York: Aldine de Gruyter, pp. 115-125.

Keith A (1949) A New Theory of Human Evolution. London: Watts.

Kimura M (1977) A Bibliography of Age Determination of Mammals (with Special Emphasis on the Cetacea). Available on request from the National Oceanic and Atmospheric Administration National Marine Fisheries Service, Southwest Fisheries Center, La Jolla, CA 92038 USA (278 pp.).

Klevezal GA, and Kleinenberg SE (1969) Age determination of mammals from annual layers in teeth and bones. Israel Prog. Sci. Trans. Jerusalem TT 69 . 55033:1-128.

Koch PL, Fisher DC, and Dettman D (1989) Oxygen isotope variation in the tusks of extinct proboscideans: A measure of season of death and seasonality. Geology 17:515-519.

Koski K, and Garn SM (1957) Tooth eruption sequence in fossil and modern man. Am. J. Phys. Anthropol. 15:469-488.

Lancaster JB (1978) Carrying and sharing in human evolution. Hum. Nature 1 (February):82-89.

Leakey MG, and Leakey RE (1978) Koobi Fora Research Project, Vol. 1. Oxford: Clarendon.

Legoux P (1966) Détermination de l'Age Dentaire de Fossiles de la Lignée Humaine. Paris: Librairie Maloine.

Lewin R (1987) Debate over emergence of human tooth pattern. Science 235:748-750.

Lewis AB, and Garn SM (1960) The relationship between tooth formation and other maturational factors. Angle Orthod. 30:70-77.

Lillegraven JA, Thompson SD, McNab BK, and Patton JL (1987) The origin of eutherian mammals. Biol. J. Linn. Soc. 32:281-336.

Lovejoy AO (1922) The length of human infancy in eighteenth-century thought. J. Philos. 19:381-385.

Lovejoy CO (1981) The origin of man. Science 211:341350.

Mann AE (1968) The Paleodemography of Australopithecus. Ph.D. dissertation, The University of California, Berkeley.

Mann A (1972) Hominid and cultural origins. Man 7:379-386.

Mann AE (1975) Paleodemographic Aspects of the South African Australopithecines. Philadelphia: University of Pennsylvania.

Mann A (1988) The nature of Taung dental maturation. Nature 333:123.
Mann AE, Lampl M, and Monge J (1987) Maturational patterns in early hominids. Nature 328:673-675.

Mann AE, Lampl M, and Monge J (1990) Patterns of ontogeny in human evolution: Evidence from dental development. Yrbk. Phys. Anthropol. 33:111-150.

Martin RD (1983) Human Brain Evolution in an Ecological Context. Fifty-second James Arthur Lecture on the Evolution of the Human Brain. New York: American Museum of Natural History.

McCown TD, and Keith A (1939) The Stone Age of Mount Carmel, Vol. II. Oxford: Clarendon.

McHenry HM (1988) New estimates of body weight in early hominids and their significance to encephalization and megadontia in "robust" australopithecines. In FE Grine (ed.): Evolutionary History of the "Robust" Australopithecines. New York: Aldine de Gruyter, pp. 133-148.

Montagu MFA (1962) Time, morphology, and neoteny in the evolution of man. In MFA Montagu (ed.): Culture and the Evolution of Man. New York: Oxford University Press, pp. 324-342.

Moorrees CFA, Fanning EA, and Hunt EE (1963) Age variation of formation stages for ten permanent teeth. J. Dent. Res. 42:1490-1502.

Murchison MA, Riopelle AJ, and Owsley DW (1988) Dental development in protein-deprived infant rhesus monkeys. Hum. Biol. 60:383-394.

Neville AC (1967) Daily growth layers in animals and plants. Biol. Rev, 42:421-441.

Nissen HW, and Riesen AH (1964) The eruption of the permanent dentition of chimpanzee. Am. J. Phys. Anthropol. 22:285-294.

Niswander JD, and Sujaku C (1965) Permanent tooth eruption in children with major physical defect and disease. J. Dent. Child. 32:266-268.

Okada M (1943) Hard tissues of animal body: Highly interesting details of Nippon studies in periodic patterns of hard tissues are described. Shanghai Evening Post, spec. ed.: Health, Recreation and Medical Progress, 26:15-31.

Pianka ER (1970) On $r$ and $K$ selection. Am. Nat. 104:592-597.

Pilbeam D (1972) Adaptive response of hominids to their environment as ascertained by fossil evidence. Social Biol. 19:115-127.

Pilbeam D (1980) Major trends in human evolution. In LK Konigsson (ed.): Current Argument on Early Man. New York: Pergamon, pp. 261-285.

Pond CM (1977) The significance of lactation in the evolution of mammals. Evolution 31:177-199.

Potts $R$ (1988) Early Hominid Activities at Olduvai. New York: Aldine de Gruyter.

Sacher GA (1959) Relation of lifespan to brain weight and body weight in mammals. In GEW Wolstenholme and M O'Conner (eds.): CIBA Foundation Colloquia on Ageing, Vol. V.: The Lifespan of Animals. London: Churchill, pp. 115-133.

Sacher GA (1975) Maturation and longevity in relation to cranial capacity in hominid evolution. In RH Tuttle (ed.): Primate Functional Morphology and Evolution. The Hague: Mouton, pp. 417-441.

Sacher GA (1978) Longevity, aging, and death: An evolutionary perspective. Gerontologist 18:112-119.

Sacher GA, and Staffeldt EF (1974) Relation of gestation time to brain weight for placental mammals. Am. Nat. 108:593-616.

Scheffer VB, and Myrick AC (1980) A review of studies to 1970 of growth layers in the teeth of marine mammals. Rep. Int. Whal. Commn. (Spec. Iss. 3), pp. 51-63. 
Schour I, and Poncher HG (1937) Rate of apposition of enamel and dentin, measured by the effects of acute fluorosis. Am. J. Dis. Child. 54:757-785.

Schultz AH (1935) Eruption and decay of the permanent teeth in primates. Am. J. Phys. Anthropol. 19:489581.

Schultz AH (1960) Age changes in primates and their modification in man. In $\vec{J} M$ Tanner (ed.): Human Growth. Oxford: Pergamon, pp. 1-20.

Schultz AH (1969) The Life of Primates. New York: Universe Books.

Senyurek MS (1955) A review of the order of eruption of the permanent teeth in fossil hominids. Turk Tarih Kurumu Bell. 19:407-444.

Shigehara N (1980) Epiphyseal union, tooth eruption, and sexual maturation in the common tree shrew, with reference to its systematic problem. Primates 21:1-19.

Simons EL (1989) Human origins. Science 245:13431350.

Simpson SW, Lovejoy CO, and Meindl RS (1990) Hominoid dental maturation. J. Hum. Evol. 19:285-297.

Skinner MF, and Sperber GH (1982) Atlas of Radiographs of Early Man. New York: Alan R. Liss.

Smith BH (1986) Dental development in Australopithecus and early Homo. Nature 323:327-330.

Smith BH (1987) Reply to "Maturational patterns in early hominids" by AE Mann, M Lampl, and J Monge. Nature 328:674-675.

Smith BH (1989a) Dental development as a measure of life history in primates. Evolution 43:683-688.

Smith BH (1989b) Growth and development and its significance for early hominid behaviour. Ossa 14:6396.

Smith BH (1991a) Age of weaning approximates age of emergence of the first permanent molar in nonhuman primates, abstracted. Am. J. Phys. Anthropol. Suppl. 12 , pp. 163-164.

Smith BH (1991b) Standards of human tooth formation and dental age assessment. In M Kelley and CS Larsen (eds.): Advances in Dental Anthropology. New York: Wiley-Liss, pp. 143-168.

Smith BH (1991c) Physiological age of KNM-WT 15000 and its significance for growth and development of an extinct species. In AC Walker and REF Leakey (eds.): The Nariokotome Homo erectus Skeleton. Cambridge: Belknap Press of Harvard University (in press).
Stern JT, and Susman RL (1983) The locomotor anatomy of Australopithecus afarensis. Am. J. Phys. Anthropol. 60:279-317

Swindler DR, Olshan AF, and Sirianni JE (1982) Sex differences in permanent mandibular tooth development in Macaca nemestrina. Hum. Biol. 54:45-52.

Tarrant LH, and Swindler DR (1972) The state of the deciduous dentition of a chimpanzee fetus (Pan trog. lodytes). J. Dent. Res. 51:677.

Tobias PV (1967) The Cranium and Maxillary Dentition of Australopithecus (Zinjanthropus) boisei, Olduvai Gorge, Vol. 2. Cambridge: Cambridge University.

Tobias PV (1968) The age of death among the australopithecines. Anthropologist (Dehli) (Special Vol.), pp 23-28.

Tobias PV (1971) The Brain in Hominid Evolution. New York: Columbia University.

Trinkaus E (1984) Neandertal pubic bone morphology and gestation length. Curr. Anthropol. 25:509-514.

Vallois H (1937) La durée de la vie chez l'homme fossile. L'Anthropologie 47:499-532.

Washburn SL (1960) Tools and human evolution. Sci. Am. 203:63-75.

Weidenreich F (1936) The mandibles of Sinanthropus pekinensis: A comparative study. Palaeontol. Sin., Ser. D, vol. 7, fasc. 3 .

Weidenreich F (1937) The dentition of Sinanthropus pekinensis: A comparative odontography of the hominids. Palaeontol. Sin., n.s. $1: 120-180$.

Weidenreich $F$ (1939) The duration of life of fossil man in China and the pathological lesions found in his skeleton. Chin. Med. J. 55:34-44.

White TD (1977) New fossil hominids from Laetoli Tanzania. Am. J. Phys. Anthropol. 46:197-230.

Widdowson EM, and McCance RA (1960) Some effects of accelerating growth. I. General somatic development. Proc. R. Soc. Lond. [Biol.] 152:188-206.

Wolpoff MH (1973) The single species hypothesis and early hominid evolution. In DW Lathrap and J Douglas (eds.): Variation in Anthropology. Urbana, IL: Illinois Archaeological Survey, pp. 5-15.

Wolpoff MH (1984) Evolution in Homo erectus: The question of stasis. Paleobiology 10:389-406.

Yilmaz S, Newman HN, and Poole DFG (1977) Diurnal periodicity of von Ebner growth lines in pig dentine. Arch. Oral Biol. 22:511-513. 